\section{Disability among attendees with schizophrenia in a Nigerian hospital: further evidence for integrated rehabilitative treatment designs}

\author{
Andrew Toyin Olagunju, 1 \\ Dapo Adebowale Adegbaju,2 \\ Richard Uwakwe 3
}

1Department of Psychiatry, College of

Medicine, University of Lagos; ${ }^{2}$ Federal

Neuropsychiatric Hospital, Yaba, Lagos;

3Faculty of Medicine, Nnamdi Azikiwe

University, Anambra State, Nigeria

\section{Abstract}

Evidence-based rehabilitative treatment is constrained due to limited knowledge about disability and its related factors among individuals with schizophrenia across West Africa. This study aims to investigate the pattern of disability, and the associated factors among individuals with schizophrenia. One hundred consecutively recruited consenting participants were subjected to designed questionnaire to inquire about their demographic and illness-related variables. This was followed by the administration of Structured Clinical Interview for DSM-IV-TR Axis I Disorders and Brief Psychiatric Rating Scale to confirm the diagnosis of schizophrenia and rate severity of symptoms respectively in them. In addition, the World Health Organisation Disability Assessment Scale II (WHODAS-II) was used to assess for disability in all participants. Different degrees of disability based on WHODAS-II mean score of $27.02 \pm 3.49$ were noted among individuals with schizophrenia, and affectation of domains of disability like self care, getting along with others, life activities and participation in the society among others were observed. In addition, high level of disability was significantly associated with younger adults in the age group 18-44 years $(\mathrm{P}=0.007)$, unemployment status $(\mathrm{P}=0.003)$, remittance source of income $(\mathrm{P}=0.034)$ and ethnicity $(\mathrm{P}=0.017)$; conversely, less number of children $(\mathrm{P}=0.033)$, less amount spent on treatment $(\mathrm{P}<0.001)$ and lower BPRS score $(\mathrm{P}<0.001)$ correlated negatively with high level of disability. In spite of clinical stability following treatment, individuals with schizophrenia were disabled to varied degrees, and socioeconomic as well as illness-related factors constituted important correlates. Integration of rehabilitation along with social intervention into treatment design to reduce disability is implied, and further research is also warranted.

\section{Introduction}

Schizophrenia is a chronic debilitating mental illness with socioeconomic and public health significance due to the remarkable and life-long health care needs among those affected globally. The economic cost of schizophrenic illness is not only linked to the significant cost of care based on its chronic course, but also largely due to the indirect cost resulting from its disabling effects linked to the loss of skills needed for productive life in affected individuals. ${ }^{1}$ As a mental health syndrome, the symptoms of schizophrenia are sometimes grouped as positive, negative and other additional symptoms. The key positive symptoms include delusion, thought interference or passivity and hallucination among others. Whereas, negative symptoms include loss of the normal level of motivation or drive, loss of awareness of socially appropriate behaviour, flattening of mood and difficulty in abstract reasoning or thinking. ${ }^{2,3}$ In general, the negative symptoms are more resistant to treatment, more disabling and connote poorer prognosis. ${ }^{4}$

The presentation of disability in schizophrenia is such that there may be restriction or lack of ability to perform an activity in the manner or within the range considered normal for a human being. Such disability is specifically concerned with compound or integrated activities of the body as a whole (e.g. task, skills and behaviour), and includes excesses or deficiencies of customarily expected activities and behaviour. For easy assessment of disability in chronic medical conditions, the International Classification of Functioning, Disability and Health (ICF) classified the affected domains from the perspective of body, individual and society. The domains for assessment were done by listing body functions and structure as well as activity and participation. Since an individual's functioning and disability occurs in a context, the ICF also included a list of environmental factors. ${ }^{5,6}$ In relation to disability, schizophrenia ranks third after quadriplegia and dementia globally, ${ }^{7}$ and research has shown that negative symptoms contribute much more to functional disability, poorer quality of life, and caregivers burden than the positive symptoms. ${ }^{4,8} \mathrm{~A}$ deficit in patients' ability to care for themselves and to meet the expectations of others are the root challenges faced by people with schizophrenia and connected with disability. ${ }^{9}$ In spite of treatment, individuals with schizophrenia contend with significant level of disability based on evidence from extant literature that are preponderantly from western populations. For instance,
Correspondence: Andrew Toyin, Olagunju Department of Psychiatry, College of Medicine, University of Lagos, PMB 12003, Lagos, Nigeria.

E-mail: aolagunju@unilag.edu.ng,

andyolagus@yahoo.com

Key words: Associated factors; Disability; Rehabilitation; Schizophrenia; Social intervention.

Contributions: the authors contributed equally.

Conflict of interest: the authors declare no potential conflict of interest.

Received for publication: 18 June 2016.

Revision received: 14 October 2016.

Accepted for publication: 17 October 2016.

This work is licensed under a Creative Commons Attribution-NonCommercial 4.0 International License (CC BY-NC 4.0).

(C) Copyright A.T. Olagunju et al., 2016

Licensee PAGEPress, Italy

Mental Illness 2016; 8:6647

doi:10.4081/mi.2016.6647

Harding et al.10 reported in a long term followup of profoundly disabled patients with schizophrenia for 20-25 years after release from the hospital that they had sixteen years of schizophrenic symptoms and ten years of disability. Thus, a clearer picture of the disability associated with mental disorders may need assessment of the number of previous episodes, average length of episodes, the average time between episodes, inter-episode psychosocial functioning and response to treatment among others. ${ }^{1}$ The measure of good outcome in the care of people living with chronic mental illnesses including schizophrenia is shifting from assessment of remission of symptoms alone, to include recovery from all dimensions of impairments. To ensure the foregoing, rehabilitation and social measures ${ }^{11}$ geared towards addressing impairments to assist reintegration of individuals with schizophrenia into a productive socio-economic life have been advocated for inclusion in mental health interventions against schizophrenia. In this light, our study was aimed to expand the scanty research in the field by investigating the pattern of disability and associated factors in stable individuals with schizophrenia so as to promote evidence-planned rehabilitation, and recovery into productive life among individuals with schizophrenia across the West African region. We postulated that individuals with schizophrenia would experience varied degrees of disability, and identifiable socioeconomic along with illness-related factors would constitute identifiable determinants of disability. 


\section{Materials and Methods}

This cross sectional study was carried out at the outpatient department of a Nigerian hospital in West Africa. The inclusion criteria were subjects aged between 18-64 years, duration of illness and treatment $\geq 6$ months, and those who gave informed consent. While the exclusion criteria were evidence of obvious head injury or injury to any part of the nervous system and refusal to participate. Consecutive patients that satisfied the inclusion criteria were interviewed till the calculated sample size was obtained. The calculated sample size was one hundred participants based on Fliess ${ }^{12}$ formula. Ethical permission was sought and obtained from the ethical committee of the hospital by sending the proposal to the committee before commencement of the study. All participants gave informed consent, their confidentiality was strictly maintained and voluntary refusal or disengagement at any point of the interview without any negative consequence on their treatment was allowed.

The following instruments were administered to all participants:

1. Questionnaire: A designed socio-demographic and clinical questionnaire inquiring about socio-demographic data of the participants including age, sex, ethnicity, religion, marital status, occupation, educational level, source of income, income per month, amount spent on treatment per month, residential type and living condition. Illnessrelated variables were also incorporated into the questionnaire including duration of the illness and number of hospitalization.

2. Structured Clinical Interview for DSM-IV-TR Axis I Disorders (SCID):13 This is a semistructured interview for making major DSMIV-TR axis I diagnosis. The SCID-P version was used in this study and only the module on schizophrenia was used. This instrument detects lifetime prevalence and current episode (one-month). Scoring is from 0-3. A score of zero denotes inadequate information, one denotes absence, two denotes subthreshold and three denotes threshold. The instructment enjoys good validity property in this context and has been well used in Nigeria. ${ }^{14}$

3. Brief Psychiatric Rating Scale (BPRS): 15 This is an 18-item scale that measures psychotic and non-psychotic symptoms in major psychiatric illness especially schizophrenia. The 18 items are scored on a seven-point scale, $\quad(1=$ not present, $7=$ extremely severe). The scale assesses tension, emotional withdrawal, mannerisms, motor retardation, and uncooperativeness, conceptual disorganization, thought content, anxiety, guilt feelings, grandiosity, depressive mood, hostility, somatic concerns, hallucinatory behaviour, suspiciousness, blunted affect, excitement and disorientation. The BRS has been used extensively in Nigeria. 16,17

4. World Health Organisation Disability Assessment Scale II (WHODAS-II):18 The 36item interviewer-administered version of WHODAS-II was used in this study. It measures the difficulty the individual has had with performing particular daily activities over a period of 30 days. It consists of 36 Likert formatted questions, divided into six domains and scored as $1=$ none, $2=$ mild, $3=$ moderate, $4=$ severe, $5=$ extreme. The total maximum score of 180 is converted to 0 -100 with higher scores depicting more disability. It is of note that this instrument has been used in previous research works in this context. ${ }^{19,20}$

The researchers had training in the use of the instruments before commencement of the study. Data were analysed using the Statistical Package for Social Sciences, seventeenth edition (SPSS-17). ${ }^{21}$ Additional information on study population, sampling and procedure were described in earlier works. ${ }^{19}$ For analyses, participants were dichotomised such that those scoring above the mean score on WHODAS-II 18 were regarded as reporting high level of disability, and those below mean score as not.

Table 1. Distribution socio-demographic profile of participants.

\begin{tabular}{|c|c|c|}
\hline Variables & N & $\%$ \\
\hline $\begin{array}{l}\text { Age group } \\
\text { 18-44 years } \\
45-64 \text { years }\end{array}$ & $\begin{array}{l}75 \\
25\end{array}$ & $\begin{array}{l}75 \\
25\end{array}$ \\
\hline $\begin{array}{l}\text { Sex } \\
\quad \text { Male } \\
\quad \text { Female }\end{array}$ & $\begin{array}{l}45 \\
55\end{array}$ & $\begin{array}{l}45 \\
55\end{array}$ \\
\hline $\begin{array}{l}\text { Marital Status } \\
\text { Single } \\
\text { Married } \\
\text { Seperated } \\
\text { Divorced }\end{array}$ & $\begin{array}{c}65 \\
36 \\
6 \\
3\end{array}$ & $\begin{array}{c}65 \\
36 \\
6 \\
3\end{array}$ \\
\hline $\begin{array}{l}\text { No of Children } \\
\text { None } \\
\text { One } \\
\text { Two } \\
\text { Three } \\
\text { >Three }\end{array}$ & $\begin{array}{c}56 \\
18 \\
13 \\
4 \\
9\end{array}$ & $\begin{array}{l}56 \\
18 \\
13 \\
4 \\
9\end{array}$ \\
\hline $\begin{array}{l}\text { Education Status } \\
\text { None } \\
\text { Primary Uncompleted } \\
\text { Primary Completed } \\
\text { Secondary Uncompleted } \\
\text { Secondary Completed } \\
\text { Tertiary Uncompleted } \\
\text { Tertiary Completed }\end{array}$ & $\begin{array}{c}2 \\
2 \\
13 \\
8 \\
55 \\
4 \\
16\end{array}$ & $\begin{array}{c}2 \\
2 \\
13 \\
8 \\
55 \\
4 \\
16\end{array}$ \\
\hline $\begin{array}{c}\text { Employment Status } \\
\text { Employed } \\
\text { Unemployed }\end{array}$ & $\begin{array}{l}45 \\
55\end{array}$ & $\begin{array}{l}45 \\
55\end{array}$ \\
\hline $\begin{array}{l}\text { Religion } \\
\text { Christianity } \\
\text { Islam }\end{array}$ & $\begin{array}{l}73 \\
27\end{array}$ & $\begin{array}{l}73 \\
27\end{array}$ \\
\hline $\begin{array}{l}\text { Ethnicity } \\
\text { Yoruba } \\
\text { Ibo } \\
\text { Edo } \\
\text { Urhobo } \\
\text { Others }\end{array}$ & $\begin{array}{c}77 \\
7 \\
5 \\
2 \\
9\end{array}$ & $\begin{array}{l}77 \\
7 \\
5 \\
2 \\
9\end{array}$ \\
\hline $\begin{array}{l}\text { Source of income } \\
\text { Salary } \\
\text { Personal Business } \\
\text { Remittance }\end{array}$ & $\begin{array}{l}18 \\
27 \\
55\end{array}$ & $\begin{array}{l}18 \\
27 \\
55\end{array}$ \\
\hline Total & 100 & $100 \%$ \\
\hline
\end{tabular}




\section{Results}

\section{Socio-demographic profile of par- ticipants}

Majority of the study participants, consisting of three-fourths (75\%) belonged to the age group 18-44 years, while 55\% were females. Similar proportions of the participants were single (55\%) and had no children (56\%). A little above half of the participants, made up of $55 \%$ each completed secondary school and were unemployed. The largest proportions of the participants were Christians (73\%) and belonged to the Yoruba ethnic group (77\%). Fifty-five participants relied on remittance, while the remaining earned money from their jobs (Table 1).

\section{Treatment-related variables among participants}

The mean age of participants was $37.35( \pm 9.48)$ years, and mean illness duration was $9.90( \pm 6.75)$ years. Majority of the participants (91\%) earned less than 20,000 ( \$127) monthly given the background of an average income of $18,000(\sim 114)$ monthly set as the national minimum wage. ${ }^{22}$ More participants (85\%) spent less than 2,000 ( $\$ 13)$ on medications and those that spent less than 1000 ( \$6.3) monthly were more (58\%). Thirtythree participants each were living with their parents and spouse/children respectively. Majority of the participants (81\%) lived in homes with more than one room. Similar proportions of participants reported illness duration ranging 1-10 years (58\%) and previous hospital admission (57\%) (Table 2).

\section{Pattern of disability among partici- pants}

The mean score for participants on WHODAS-II 18 was $27.02( \pm 3.49)$, and the scores ranged from 21.11-40.00. This mean score was used to dichotomize participants into those above and below average WHODAS-II 18 score. The most affected domain with respect to disability among participants was participation in the society, while the least impairment was seen in the domain on self-care. Life activities were more impaired in participants compared to getting along with others (Table 3 ).

\section{Relationship between socio-demo- graphic attributes and WHODAS-II}

Following dichotomization, $57 \%$ of participants scored below the mean score (27.02) on WHODAS-II.18 Participants within the age group $18-44$ years $(\mathrm{P}=0.007)$, that were unemployed $(\mathrm{P}<0.001)$, relying on remittance $(\mathrm{P}=0.034)$ and belonging to the Yoruba ethnic group $(\mathrm{P}=0.017)$ were more likely to report scores above the mean score on WHODAS-II18. Whereas participants with no children
$(\mathrm{P}=0.033)$ were significantly over-represented among those that scored below the mean score. The participants who scored above and below the mean score on WHODAS-II 18 were not significantly different with respect to educational status $(\mathrm{P}=0.438)$, gender $(\mathrm{P}=0.508)$, religion $(\mathrm{P}=0.861)$ and marital status $(\mathrm{P}=0.128)$ (Table 4).

\section{Relationship between treatments related variables and WHODAS-II}

Participants that spent less than 2000 $(\sim \$ 127)$ on medications were more likely to score below the mean score on WHODAS-II ${ }^{18}$ compared to those that scored above the mean score $(\mathrm{P}<0.001)$. However, the living condition

Table 2. Treatment related variables among participants.

\begin{tabular}{|c|c|c|}
\hline Variables & $\mathbf{N}$ & $\%$ \\
\hline $\begin{array}{l}\text { Income per month } \\
\quad<10,000 \\
10,000-20,000 \\
20,001-30,000 \\
30,001-40,000 \\
40,001-50,000\end{array}$ & $\begin{array}{c}58 \\
33 \\
5 \\
1 \\
3\end{array}$ & $\begin{array}{c}58 \\
33 \\
5 \\
1 \\
3\end{array}$ \\
\hline $\begin{array}{l}\text { Amount spent on treatment } \\
\quad<1000 \\
1001-2000 \\
2001-3000 \\
3001-4000 \\
4001-5000 \\
>5000\end{array}$ & $\begin{array}{c}58 \\
27 \\
8 \\
5 \\
1 \\
1\end{array}$ & $\begin{array}{l}58 \\
27 \\
8 \\
5 \\
1 \\
1\end{array}$ \\
\hline $\begin{array}{l}\text { Living conditions } \\
\text { Alone } \\
\text { With spouse } \\
\text { Spouse and Children } \\
\text { Children } \\
\text { Parents } \\
\text { Other relatives } \\
\text { Friends }\end{array}$ & $\begin{array}{c}16 \\
4 \\
32 \\
3 \\
36 \\
7 \\
2\end{array}$ & $\begin{array}{c}16 \\
4 \\
32 \\
3 \\
36 \\
7 \\
2\end{array}$ \\
\hline $\begin{array}{l}\text { Residential type } \\
\text { One room } \\
\text { Room and Parlour } \\
\text { Two Bedroom Flat } \\
\text { Three Bedroom Flat }\end{array}$ & $\begin{array}{l}19 \\
42 \\
28 \\
11\end{array}$ & $\begin{array}{l}19 \\
42 \\
28 \\
11\end{array}$ \\
\hline $\begin{array}{c}\text { Illness duration } \\
1-10 \text { years } \\
11-20 \text { years } \\
>20 \text { years }\end{array}$ & $\begin{array}{c}58 \\
36 \\
6\end{array}$ & $\begin{array}{c}58 \\
36 \\
6\end{array}$ \\
\hline $\begin{array}{l}\text { No of Hospitalization } \\
\text { None } \\
\text { One } \\
\text { Two } \\
\text { Three }\end{array}$ & $\begin{array}{c}43 \\
28 \\
22 \\
5\end{array}$ & $\begin{array}{c}43 \\
28 \\
22 \\
5\end{array}$ \\
\hline Four & 2 & 2 \\
\hline Age (Years) & $37.35 \pm 9.48$ & \\
\hline Illness duration (Years) & $9.90 \pm 6.75$ & \\
\hline Illness range (Years) & $01-37$ & \\
\hline
\end{tabular}

Table 3. Summary statistics of WHODAS of participants.

\begin{tabular}{lccc} 
WHODAS & Mean & SD & Range \\
Overall & 27.02 & 3.49 & \multirow{2}{*}{$21.11-40.00$} \\
Domain 1: Understanding and communication & 3.42 & 0.351 & \\
\hline Domain 2: Getting around & 3.27 & 0.44 & \\
Domain 3: Self-care & 2.23 & 0.05 & \\
\hline Domain 4: Getting along with others & 4.46 & 1.16 & \\
Domain 5: Life activities & 5.15 & 0.82 & \\
\hline Domain 6: Participation in the society & 8.48 & 1.85 &
\end{tabular}


( $\mathrm{P}=0.406)$, residential type $(\mathrm{P}=0.755)$, income per month $(\mathrm{P}=0.258)$, duration of illness $(\mathrm{P}=0.834)$, and number of hospitalization $(\mathrm{P}=0.867)$ were not significantly different between participants with scores above or below the mean score on WHODAS-II'18 (Table 5).

\section{Association of BPRS scores with WHODAS-II scores}

The mean score for participants on the BPRS 15 was $25.84( \pm 4.45)$, and the scores ranged from 19-41. BPRS15 score was significantly higher in participants with scores above the mean score on WHODAS-II18 than those that scored below the mean $(\mathrm{t}=-6.085$, $\mathrm{P}<0.001)$.

\section{Discussion and Conclusions}

Clinical stabilization of individuals with schizophrenia is considered a cardinal goal in most treatment models. ${ }^{1}$ However, given the level of psychosocial impairments frequently seen in people with schizophrenia despite treatment, the evaluation of illness with respect to functioning outcome among affected individuals is germane. Particularly because such assessment can provide the evidence needed to develop informed and comprehensive psychosocial management of schizophrenia targeted towards ameliorating the disability suffered by the affected population. In this light, our study report some important findings that include varied levels of disability among individuals with schizophrenia, com- prising affections in domains that assessed self-care, getting along with others, life activities and participation in the society among others. Further, high level of disability was more likely to be linked with the young adults in the age group 18-44 years, unemployment status, remittance source of income and Yoruba ethnic group; while participants who spent less on treatment, had less number of children, and had lower BPRS ${ }^{15}$ score were less likely to report high level of disability.

In this study, it is not surprising that gender was not observed to be associated with disability, especially because approximately equal male: female ratio was observed, and this was also similar to the gender ratio fielded in other works on schizophrenia.23,24 With regards to ethnicity, most participants were not only found to be of Yoruba extraction in agreement

Table 4. Association between socio-demographic profile and WHODAS-II.

\begin{tabular}{|c|c|c|c|c|c|}
\hline Variables & DDAS, mean n (\%) & Above WHODAS, mean n (\%) & Total (\%) & TOS & P-value \\
\hline \multicolumn{6}{|l|}{ Age group } \\
\hline 18-44 years & 37 (37) & $38(38)$ & $75(75)$ & \multirow[t]{2}{*}{2.756} & \multirow[t]{2}{*}{0.007} \\
\hline $45-64$ years & $20(20)$ & $5(5)$ & $25(25)$ & & \\
\hline \multicolumn{6}{|l|}{ Sex } \\
\hline Male & $24(24)$ & $21(21)$ & $45(45)$ & \multirow[t]{2}{*}{-0.665} & \multirow[t]{2}{*}{0.508} \\
\hline Female & $33(33)$ & $22(22)$ & $55(55)$ & & \\
\hline \multicolumn{4}{|l|}{ Marital Status } & \multirow[t]{5}{*}{1.537} & \multirow[t]{5}{*}{0.128} \\
\hline Single & $25(25)$ & $30(30)$ & $55(55)$ & & \\
\hline Married & $26(26)$ & $10(10)$ & $36(36)$ & & \\
\hline Seperated & $5(5)$ & $1(1)$ & $6(6)$ & & \\
\hline Divorced & $1(1)$ & $2(2)$ & $3(3)$ & & \\
\hline \multicolumn{4}{|l|}{ No of Children } & \multirow[t]{6}{*}{2.158} & \multirow[t]{6}{*}{0.033} \\
\hline None & $26(26)$ & $30(30)$ & $56(56)$ & & \\
\hline One & $11(11)$ & $7(7)$ & $18(18)$ & & \\
\hline Two & $11(11)$ & $2(2)$ & $13(13)$ & & \\
\hline Three & $3(3)$ & $1(1)$ & $4(4)$ & & \\
\hline$>$ Three & $6(6)$ & $3(3)$ & $9(9)$ & & \\
\hline \multicolumn{4}{|l|}{ Education Status } & \multirow[t]{8}{*}{-0.779} & \multirow[t]{8}{*}{0.438} \\
\hline None & $1(1)$ & $1(1)$ & $2(2)$ & & \\
\hline Primary Uncompleted & $2(2)$ & $0(0)$ & $2(2)$ & & \\
\hline Primary Completed & $7(7)$ & $6(6)$ & $13(13)$ & & \\
\hline Secondary Uncompleted & $4(4)$ & $4(4)$ & $8(8)$ & & \\
\hline Secondary Completed & $35(35)$ & $20(20)$ & $55(55)$ & & \\
\hline Tertiary Uncompleted & $0(0)$ & $4(4)$ & $4(4)$ & & \\
\hline Tertiary Completed & $8(8)$ & $8(8)$ & $16(16)$ & & \\
\hline \multirow{2}{*}{\multicolumn{4}{|c|}{ Employment Status }} & \multirow[t]{3}{*}{-3.095} & \multirow[t]{3}{*}{0.003} \\
\hline & $33(33)$ & $12(12)$ & $45(45)$ & & \\
\hline Unemployed & $24(24)$ & $31(31)$ & $55(55)$ & & \\
\hline & \multirow[t]{3}{*}{0.176} & \multirow[t]{3}{*}{0.861} \\
\hline Christianity & $42(42)$ & $31(31)$ & $73(73)$ & & \\
\hline Islam & $15(15)$ & $12(12)$ & $27(27)$ & & \\
\hline \multicolumn{4}{|l|}{ Ethnicity } & \multirow[t]{6}{*}{2.420} & \multirow[t]{6}{*}{0.017} \\
\hline Yoruba & $49(49)$ & $28(28)$ & 77 (77) & & \\
\hline Ibo & $3(3)$ & $4(4)$ & $7(7)$ & & \\
\hline Edo & $2(2)$ & $3(3)$ & $5(5)$ & & \\
\hline Urhobo & $0(0)$ & $2(2)$ & $2(2)$ & & \\
\hline Others & $3(3)$ & $6(6)$ & $9(9)$ & & \\
\hline \multirow{4}{*}{\multicolumn{2}{|c|}{$\begin{array}{l}\text { Source of income } \\
\text { Salary } \\
\text { Personal Business } \\
\text { Remittance }\end{array}$}} & & & 2.14 & 0.034 \\
\hline & & $6(6)$ & $18(18)$ & & \\
\hline & & $7(7)$ & $27(27)$ & & \\
\hline & & $30(30)$ & $55(55)$ & & \\
\hline
\end{tabular}


with other studies done in similar location,19 but participants of the Yoruba ethnic group were more likely to report high level of disability. While this finding may seems to reflect the location of the study site in Yoruba land, it also brings to fore the potential negative effects of socio-cultural interpretations and schemas of schizophrenia that pervade delayed treatment, social exclusion and stigma among the Yorubas. For example, the attribution of supernatural causation, and connotation of schizophrenia as a form of punishment or spell may lead to stigma, delayed treatment presentation, poor response to treatment due to chronicity and high degree of disability. ${ }^{25,26}$ Such corollary and compounding impacts of cultural schemas in schizophrenia have been elucidated among populations in other contexts including Asia, South Americans, and people of colour in the west among others. ${ }^{25}$

Expectedly, high level of disability correlated positively with unemployment. Particularly because schizophrenia has been linked with notable loss of social and employable skills in several previous studies elsewhere. ${ }^{27-29}$ It is also possible that social exclusion and the disabling effects of schizophrenia are possible explanations for the high unemployment rate on one hand, while unemployment state may also be disabling among the participants in a vicious circle. In this light, the high unemployment rate may be linked to loss of job due to stigma, absenteeism and functional impairment among others following schizophrenic illness. For instance, Perkins and Renaldi 29 reported that there was decrease in employment rates among individuals with schizophrenia to whom employment discrimination is likely to be most acute as well as greater in relation to other mental disorders. Generally, people with psychiatric disorders have been frequently discriminated against by entrepreneurs as a result of dwindling performance, stereotypic belief, stigmatization and pervasive negative attitudes among others. ${ }^{30}$ More than half of the participants with schizophrenia in this study relied on remittance from relatives for their monetary needs. This monetary dependence may be related to the high unemployment rate or having to engage in low paying jobs in accordance with previous observations, ${ }^{29,31}$ that reported a decrease in employment, particularly the high paying jobs amongst patients with mental disorders, with schizophrenia being most affected. In relation to age and the number of children, participants in the age group 18-44 years were more likely to report high level of disability, while those who had less number of children were less likely to report high degree of disability. These finding are possibly a reflection of the negative interference of the illness factors with respect to early onset and chronic longitudinal course on important socio-economic and reproductive roles. Importantly, these findings seem to also mirror the disproportionately disabling affections in participation in the society and life activities that were reported. The age bracket, 18-44 years represents the significant period for productive life activities, acquisition of psychosocial skills, social interactions and engagements. Thus, the disabling impacts of

Table 5. Association between treatment related variables and WHODAS-II.

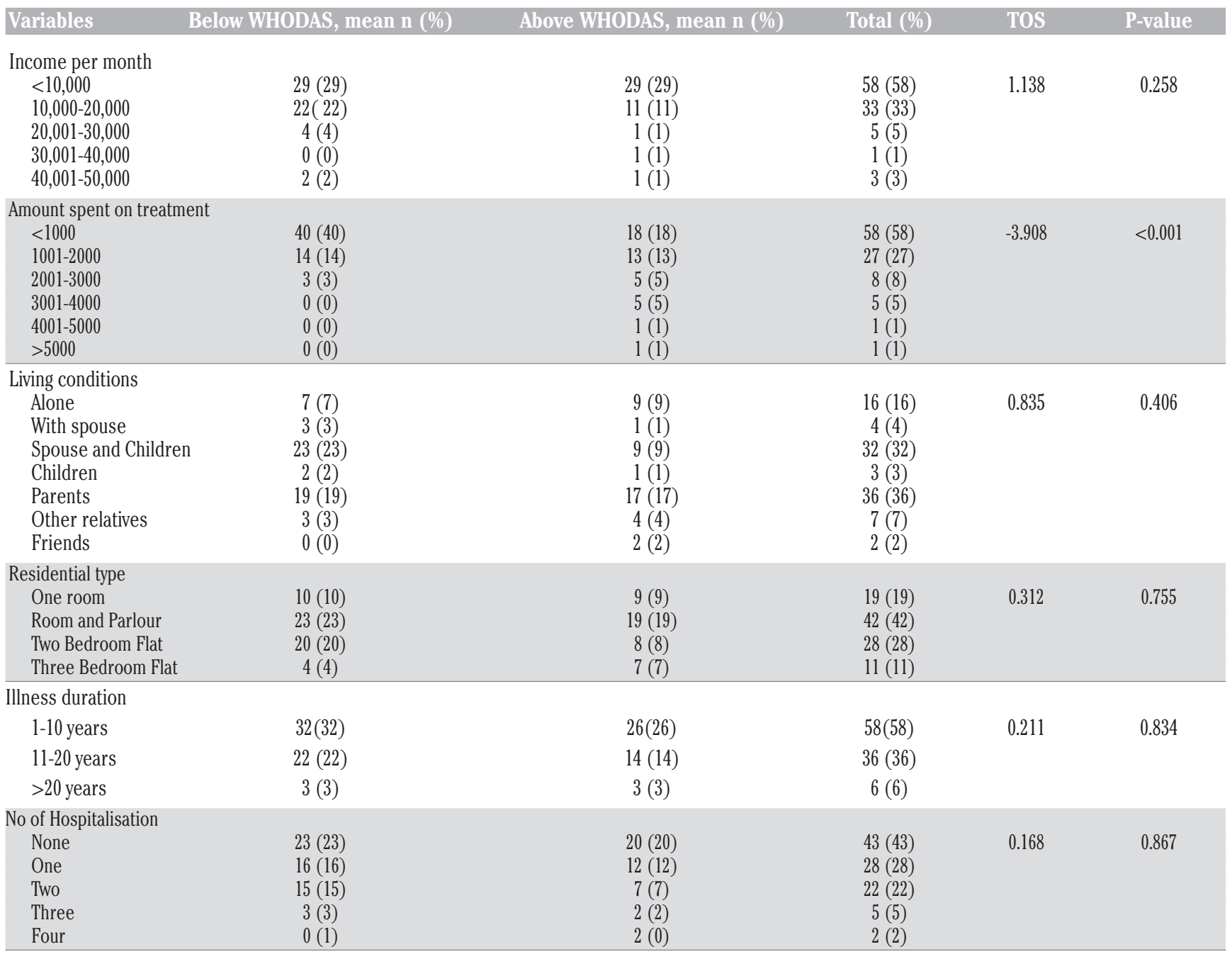


schizophrenia and deficits in skills needed for meaningful and productive activities to satisfy economic responsibilities as well as fulfill social roles are likely to more noticeable and reported in the young adults and those with more children.

In a similar trend, the severity of symptoms as indicated by increasing BPRS15 scores in participants correlated positively with higher level of disability. Specifically, BPRS15 score was significantly higher in participants that scored above WHODAS-II 18 mean score compared to those that scored below the mean score on WHODAS-II ${ }^{18}$. As it is, this finding underscores the positive role of symptom control in full recovery of individuals with schizophrenic illness from associated disability. 19,31 It is noteworthy that a little above one-third of individuals with schizophrenia affirmed living with their parents in agreement with the finding of Jabelensky et al. ${ }^{32}$ This finding exemplifies the important role of extended family support system in the care of those with chronic illnesses in this part of the world. Illness duration ranged from 1-37years in this study in contrast to a study among 18-64 year old population, 33 where the reported range of illness duration was more than the one fielded in our study. The mean illness duration was 9.9years, which is also lower than 15.04 years reported by Carr et al. ${ }^{34}$ in Australia. A plausible explanation for this finding is that illness might have been detected late here due to cultural and religious beliefs. However, duration of illness was not found to have significant correlation with disability in contrast to the report of Alli 35 that noted a significant positive correlation of disability with duration of illness.

A number of limitations were identified in this study. For example, this is a hospitalbased study done at a location with over-representation of participants from the Yoruba ethnic extraction. Thus, the results obtained may not be representative of the general population, and extrapolation to other contexts needs be done cautiously, despite the study conveying important lessons that may be potentially relevant to other contexts and ethnic groups. Further, the cross-sectional design indicates that correlates of disability do not imply causality. Disability was assessed by subjects' verbal self-report, thus several factors may affect patient's motivation to correctly identify or disclose disability as defined in the present study. In this regard, use of performance measures would more objectively clarify disability. Lastly, elements of bias could have been introduced into the study as a result of non-random selection of participants and inability to blind the investigator.

Overall, further studies are needed to address the limitations identified in this study by using more robust sample size and prospective study design with control for confounders.
In addition, more studies are needed to ascertain the causes of disability in schizophrenia. This will pave way for proactive, preventive and interventional (treatment) approaches towards reduction of disability in the population affected with schizophrenia. Although not specifically investigated in this study, an integrated recovery orientation rehabilitation with social intervention may possibly reduce disability in patients with schizophrenia. ${ }^{36}$ Such intervention could include initiating greater collaboration between hospitals and community occupational therapists that could assist in improving the social disability that individuals with schizophrenia do encounter in daily living.

\section{References}

1. Semple D, Smyth R, Burns J, et al. Oxford handbook of psychiatry, Indian edition. Oxford: Oxford University Press: 2005

2. American Psychiatric Association (APA) Diagnostic and statistical manual of mental disorders (4th edn). Washington DC: American Psychiatric Association; 1994

3. World Health Organisation (WHO) The ICD-10 Classification of mental and behavioural disorders. Clinical description and diagnostic guidelines. Geneva: World Health Organisation; 1992.

4. Gelder M, Gath D, Mayou R, Cowen P. Schizophrenia: course and prognosis. Oxford textbook of psychiatry, 3rd ed. New York: Oxford University Press Inc.; 1996.

5. World Health Organization (WHO) international classification of impairments, disabilities, and handicaps: a manual of classification relating to the consequences of disease. Geneva: World Health Organisation; 1980

6. World Health Organization (WHO) International classification of functioning, disability and health. Geneva: World Health Organisation; 2001

7. Utsun TB. The Global burden of mental disorders (commentary). Am J Public Health 1999;89:1315-8.

8. Velligan DI, Alphs LD. Negative symptoms in schizophrenia: the importance of identification and treatment. Psychiatric Times 2008;25:3.

9. Nemade R, Dombeck M. Disability and schizophrenia. 2009. Available from: MentalHelp.net

10. Harding C, Brooks GW, Ashikaga T, et al. The Vermont longitudinal study of patients with severe mental illness; II: long time outcome of subjects who retrospectively met DSM III criteria for Schizophrenia. Am J Psychiatry 1987;144:727-35.

11. Bellack AS. Psychosocial treatment in schizophrenia. Dial Clin Neurosci 2001;3: 136-7.

12. Fleiss JL. Statistical methods for rates and proportions. 2nd ed. John New: York Wiley and sons; 1981. p. 17.

13. Spitzer RL, Williams JBW, Gibbon M, et al. The structured clinical interview for DSMIIIR (SCID) 1. History, rationale and description. Arch Gen Psychiatry 1992;49:624-9.

14. Agbir TM, Audu MD, Adebowale T0, Goar SG. Depression among medical outpatient with diabetes. A cross-sectional study at Jos University Teaching Hospital. Ann Afr Med 2010;9:5-10.

15. Overall JE, Gorham DR. The brief psychiatric rating scale (BPRS): recent developments in ascertaining and scaling. Psychopharmacol Bull 1988:97-9.

16. Ajiboye P, Adelekan M. A prospective analysis of in-patient consultation-liaison psychiatry in a Nigerian Teaching Hospital. East Afr Med J 2005;81:620-5.

17. Ohaeri JU, Otote DI. Subtypes and factors of schizophrenia in an acutely ill Nigerian sample. Psychopathology 2003;36:181-9.

18. World Health Organization (WHO). WHO psychiatric disability assessment schedule II. Geneva: World Health Organization; 1988.

19. Adegbaju DA, Olagunju AT, Uwakwe R. A. Comparative analysis of disability in individuals with bipolar affective disorder and schizophrenia in a sub-Saharan African mental health hospital: towards evidence guided rehabilitation intervention. Soc Psychiatry Psychiatr Epidemiol 2013;48: 1405-15.

20. Uwakwe R, Modebe I. Disability and caregiving in old age in a Nigerian community. Niger J Clin Pract 2007;10:58-65.

21. SPSS. The Statistical Package for Social Sciences for windows version 17 (SPSS17). Chicago, Illinois, USA. 2008

22. Central Bank of Nigeria (CBN). National Minimum Wage. Available from: https:// www.cbn.gov.ng/OUT/PUBLICATIONS/.../S TABULL-2005.PDF

23. Sadock BJ, Sadock VA. Kaplan and Sadock's concise textbook of clinical psychiatry. 3rd ed. Philadelphia: Lippincott, Williams and Wilkins, 2008.

24. Peh K, Tay E. Demographical profile and clinical features of patients with bipolar disorder in an outpatient setting in Singapore. Singapore Med J 2008;49:3803.

25. Versola-Russo J. Cultural and demographic factors of schizophrenia. Int J Psychosoc Rehabil 2006;10:89-103.

26. Gureje 0, Acha RA, Odejide OA. Pathways to psychiatric care in Ibadan. Nigeria Trop Geogr Med 1995;47:125-9.

27. Bowie RC, Depp C, McGrath JA, et al. 
Prediction of real-world functional disability in chronic mental disorders: a comparison of schizophrenia and bipolar disorder. Am J Psychiatry 2010;167:1116-24.

28. Ghanem M, Gadallah M, Meky FA, et al. National survey of prevalence of mental disorders in Egypt: preliminary survey. East Mediterr Health J 2009;15:65-75.

29. Perkins, R., Rinaldi, M. Unemployment rates among patients with long-term mental health problems. Psychiatr Bull 2002;26:295-8.

30. Oyefeso AO Attitudes towards the work behaviour of ex-mental patients in Nigeria. Int J Soc Psychiatry 1994;40:2734 .
31. Campbell EA, Olagunju AT, Ogbolu RE, Aina OF Assessment of functioning among Nigerians with schizophrenia in a tertiary health facility: influence of psychopathology, socio-demographic and treatment factors. J Psychosoc Rehabil Men. Health 2015;2:35-41.

32. Jablensky A, McGrath J, Hermann H, et al. People living with psychiatric illnesses: an Australian study. 1999. Available from: http://www.psychiatry.uwa.edu.au/_data/ assets/pdf_file/0020/2311904/1999Jablensky-et-al-LowPrev-Report4AGPS.pdf

33. James OB, Omoreagba J0. Prevalence and predictors of poor medication adherence among out-patients at a psychiatric hospital in Benin City, Nigeria. Int J Psychiatry Clin Pract 2011;15:27-34.

34. Carr VJ, Neil AL, Halpin SA, Holmes S. Premorbid, psychosocial and clinical predictors of the costs of schizophrenia and other psychoses. Br J Psychiatry 2004;184: 517-25.

35. Alli A. Disability in schizophrenia and its relationship with duration of illness and age of onset. Int J Psychosocial Rehab 2009;14:37-41.

36. Davidson L, White W. The concept of recovery as an organizing principle for integrating mental health and addiction services. J Behav Health Serv Res 2007;3:109-20. 